\title{
A CONSTRUÇÃO DO PERFIL DE UM GRUPO PIBID/QUÍMICA A PARTIR DAS MEMÓRIAS COMO UM INSTRUMENTO DE COLETA DE DADOS
}

\author{
FABIELE CRISTIANE DIAS BROIETTI* \\ https://orcid.org/0000-0002-0638-3036 \\ ENIO DE LORENA STANZANI" "* \\ https://orcid.org/0000-0002-1787-0534 \\ MARIANA LAISE DESSIMONE ${ }^{11 * *}$ \\ https://orcid.org/0000-0002-9511-743
}

RESUMO: O foco central desta investigação está em discutir as potencialidades e contribuições de um instrumento de coleta de dados denominado "memórias", considerando sua capacidade de apoiar a construção de um esboço do perfil de um grupo PIBID. Os resultados apontam que o grupo se preocupa com uma formação fundamentada em referenciais teóricos da área, visando estabelecer um espaço de pesquisa que integre escola e universidade, além de incentivar a participação dos estudantes em eventos científicos. A utilização das memórias possibilitou também identificar a frequência de participação dos sujeitos nas discussões, a fim de realizar reconduções nas atividades. Destaca-se ainda a possibilidade de estender essas reflexões a outros grupos de estudo e pesquisa, com o propósito de expor potencialidades e limites do grupo. Palavras-chave: Memórias; Grupo de estudo; PIBID.

\section{LA CONSTRUCCIÓN DEL PERFIL DE UN GRUPO PIBID/OUÍMICA A PARTIR DE LAS MEMORIAS COMO UN INSTRUMENTO DE LA RECOPILACIÓN DE DATOS}

RESUMEN: El foco central de esta investigación es discutir las potencialidades y las contribuciones de un instrumento de recopilación de datos denominado "memorias", llevando en cuenta su capacidad de basar la construcción de un esbozo del perfil de un grupo PIBID. Los resultados indican que el grupo se preocupa por una formación

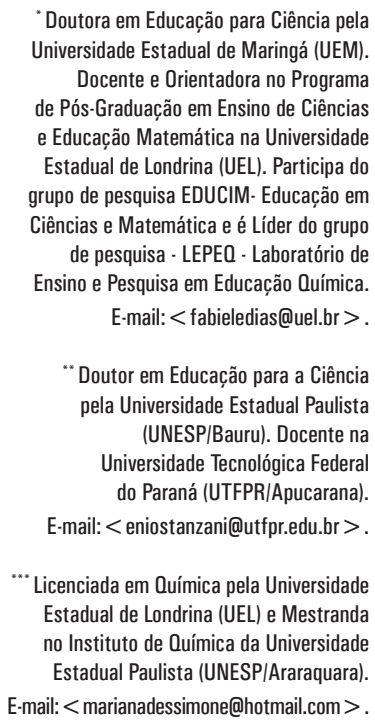

'Doutora em Educação para Ciência pela Universidade Estadual de Maringá (UEM). Docente e Orientadora no Programa de Pós-Graduação em Ensino de Ciências e Educação Matemática na Universidade Estadual de Londrina (UEL). Participa do grupo de pesquisa EDUCIM- Educação em Ciências e Matemática e é Líder do grupo de pesquisa - LEPEO - Laboratório de Ensino e Pesquisa em Educação Química. E-mail:<fabieledias@uel.br >.

“"Doutor em Educação para a Ciência pela Universidade Estadual Paulista (UNESP/Bauru). Docente na Universidade Tecnológica Federal do Paraná (UTFPR/Apucarana).

E-mail:<eniostanzani@utfpr.edu.br >

*** Licenciada em Química pela Universidade Estadual de Londrina (UEL) e Mestranda no Instituto de Química da Universidade Estadual Paulista (UNESP/Araraquara). E-mail:<marianadessimone@hotmail.com>.

\footnotetext{
' Universidade Estadual de Londrina, Programa de Pós-Graduação em Ensino de Ciências e Educação Matemática, Londrina, PR - Brasil.

" Universidade Tecnológica Federal do Paraná, Apucarana, PR - Brasil.

III Universidade Estadual Paulista, Instituto de Química, Araraquara, SP - Brasil.
} 
fundamentada en marcos teóricos del área con objeto de establecer un espacio de investigación que integre escuela y universidad, además de incentivar la participación de los estudiantes en eventos científicos. La utilización de las memorias posibilitó aun identificar la frecuencia de la participación de los sujetos en las discusiones, a fin de realizar remodelaciones en las actividades. Se destaca incluso la posibilidad de extender esas reflexiones a otros grupos de estudio e investigación, con el propósito de exponer potencialidades y límites del grupo.

Palabras clave: Memorias; Grupos de estudio; PIBID.

\section{THE CONSTRUCTION OF THE PROFILE OF A PIBID/CHEMISTRY GROUP USING THE MEMORIES AS AN INSTRUMENT OF DATA COLLECTION}

ABSTRACT: The main focus of this research is to discuss the potentialities and contributions of a data collection instrument called "memories", considering its ability to support the construction of a profile outline of a PIBID group. The results show that the group is concerned with a reasoned training in theoretical frameworks of the area, in order to establish a research environment that integrates school and university, in addition to encouraging participation of students in scientific events. The use of "memories" allowed us to identify the frequency of participation of the subjects in order to realize reappointments in the activities. We also highlight the possibility of extending these reflections to other study and research groups, with the goal OF exposing potentialities and limits of the group.

Keywords: Memories; Study group; PIBID. 
A construção do perfil de um grupo PIBID/Química a partir das memórias como um instrumento de coleta de dados

\section{INTRODUÇÃO}

O Programa Institucional de Bolsas de Iniciação à Docência (PIBID), promovido pela CAPES em âmbito nacional, surgiu com o intuito de melhorar a formação inicial e continuada dos professores, possibilitando um ensino de qualidade na Educação Básica (BRASIL, 2007).

$\mathrm{Na}$ Universidade Estadual de Londrina (UEL) o programa contemplava, em seu último edital, todas as 15 licenciaturas, nas seguintes áreas: Artes Visuais, Ciências Biológicas, Ciências Sociais, Educação Física, Filosofia, Física, Geografia, História, Letras-Espanhol, Letras-Inglês, Letras-Português, Matemática, Música, Pedagogia e Química. No subprojeto do curso de Química, intitulado "Situações de Estudo: contribuições para a Educação Científica" participavam 40 bolsistas, 06 professores supervisores, 02 professores coordenadores e 02 professores universitários, estes últimos acompanhando o grupo voluntariamente.

Uma das ações propostas consistia na elaboração e desenvolvimento de Situações de Estudo (SE) em escolas de níveis Fundamental e Médio. A SE envolve uma situação do cotidiano dos alunos sobre a qual eles têm o que dizer e no contexto da qual, eles sejam capazes de produzir novos saberes e defender seus pontos de vista, rompendo com a apresentação linear dos conteúdos científicos e desenvolvendo compreensões interdisciplinares (MALDANER; ZANON, 2001).

Outra ação do grupo consistia em reuniões quinzenais em que os participantes discutiam e planejavam as SE que seriam desenvolvidas nos colégios atendidos pelo projeto, além de realizarem seminários e discussões de artigos da área de Ensino de Ciências, a fim de fundamentar as ações desenvolvidas.

Evidenciando a riqueza das discussões e reflexões realizadas durante esses encontros e buscando, portanto, uma forma de registro e sistematização dessas informações para consultas posteriores, houve a necessidade de utilizar uma metodologia de coleta de dados de retorno rápido, já que a utilização de registros em áudio e vídeo demandaria um tempo maior, devido à necessidade de transcrição dos dados. Nesse sentido, optou-se por uma metodologia denominada "memórias", desenvolvida por Passos e colaboradores (2007; 2008).

Diante do exposto, o presente artigo tem como objetivo discutir as potencialidades e contribuições de um instrumento de coleta de dados denominado "memórias", considerando sua capacidade de apoiar a construção de um esboço do perfil ${ }^{1}$ de um grupo PIBID.

\section{AS MEMÓRIAS}

O termo "memórias" foi inspirado nos jornais de pesquisa, utilizados por diversos pesquisadores como forma de obtenção de dados. Como método de coleta de dados pode ser considerado um diário, pelo fato de nele registrar-se o cotidiano de modo livre, espontâneo: é uma ferramenta na qual o pesquisador anota suas observações e reflexões com liberdade quanto às regras e as exigências ortográficas (PASSOS et al., 2008). Na visão dos autores, 
[...] como forma de sistematização de coleta, a memória coloca-se como um primeiro passo para o trabalho do pesquisador. Cabe destacar que, o que mais nos chamou a atenção em todo esse processo é que essa forma de coleta ocorre de forma intensa, pois o pesquisador escutou, fez suas anotações (memórias), e em um momento posterior (o mais próximo possível da ocorrência do evento) irá recontar, reconstruindo o que passou, retomando o que foi ouvido e, posteriormente, disponibilizando para todo o grupo. A partir desse instante, a escrita que até então era pessoal, assume-se pública, pertence agora a todo o grupo (PASSOS et al., 2008, s/p).

As memórias têm se mostrado uma ágil ferramenta na coleta de dados, principalmente em grupos de estudos nos quais há discussões que envolvem várias pessoas ao mesmo tempo. Quando essas coletas são feitas por meio de gravações em áudio e vídeo o tempo de transcrição desses materiais é longo, ao contrário das memórias que tem um retorno rápido, tornando possível sua disponibilização a todos os participantes do grupo antes da próxima reunião, o que permite a continuação das discussões e raciocínios em andamento (PASSOS et al., 2007; 2008).

Todo esse processo torna o registro mais completo e com mais informações armazenadas, uma vez que a coleta envolve a observação e anotação, por três memoristas - produtores das memórias -, das discussões ocorridas durante as reuniões. Posteriormente, esses memoristas fazem a redação de um documento que é compartilhado com os demais membros do grupo. Essa construção coletiva possibilita que as transcrições dos diálogos sejam apresentadas de maneira detalhada, pois cada um pode trazer características diferentes ao registro produzido. Nesse sentido, as principais ações dos memoristas são escutar, escrever e disponibilizar o produzido aos demais participantes (PASSOS et al., 2007).

Ao buscar, na literatura, referenciais acerca da metodologia referida, encontramos alguns artigos e trabalhos publicados, porém todos vinculados ao grupo idealizador das memórias. Em um primeiro artigo, Passos e colaboradores (2007) buscaram analisar "a eficácia de uma técnica de coleta de dados, utilizada por um grupo de pesquisa em formação de professores, à qual se deu o nome de "memórias" (s/p). A partir de então, essa metodologia passou a ser utilizada também em outros contextos de pesquisa, como citado no segundo artigo publicado, o qual apresenta dois exemplos de aplicação (PASSOS et al., 2008). No primeiro, a coleta foi realizada por um único pesquisador, em uma situação de pesquisa que envolvia licenciandos em Matemática; no segundo exemplo, a coleta foi realizada por três pesquisadores, durante as reuniões de um grupo formado por professores de Física do Ensino Médio que atuavam no estágio supervisionado em uma licenciatura em Física.

No artigo supracitado, os autores destacam que a análise dos registros coletados por meio das memórias:

[...] pode ser uma forma de coleta adequada para o desenvolvimento de projeto de pesquisa [...] e sua agilidade de produção e o envolvimento dos pesquisadores e produtores das memórias, suplantam as fragilidades que poderiam ser evidenciadas (PASSOS et al. 2008, p.18). 
A partir das produções citadas anteriormente e da elaboração de novos registros no grupo de pesquisa, alguns trabalhos de iniciação científica foram produzidos e apresentados em eventos da área de Ensino de Ciências e Educação (OBARA et al., 2014; STANZANI; PASSOS; ARRUDA, 2011; PERES et al., 2011; SILVA; PASSOS; ARRUDA, 2010; NERI; PASSOS; ARRUDA, 2010), assim como dissertações de mestrado, as quais utilizam as memórias desenvolvidas em grupos de pesquisa a fim de investigar a formação de pesquisadores (TEIXEIRA, 2013; RIBAS, 2018).

Após apresentar os referenciais e os trabalhos produzidos utilizando esta metodologia de coleta de dados, no tópico a seguir detalhamos o contexto no qual as memórias analisadas foram produzidas.

\section{A COLETA DE DADOS E O PERCURSO METODOLÓGICO}

No grupo PIBID/Química as memórias são produzidas por três memoristas, que fazem os registros das principais discussões que acontecem durante as reuniões quinzenais do grupo. Um primeiro memorista faz a redação da memória - $1^{a}$ leitura - e a repassa para outros dois que fazem a segunda e terceira leituras, respectivamente, acrescentando informações que julgam importantes e que não constam na redação feita pelo primeiro memorista e corrigindo os possíveis equívocos encontrados. Na Figura 1 apresentamos um modelo de cabeçalho utilizado para o desenvolvimento das memórias.

Figura 1. Cabeçalho de uma memória produzida no PIBID/QUÍMICA

\section{Trabalho documental e memórias por NOME DOS MEMORISTAS}

\begin{tabular}{|l|l|}
\hline Atividade: & $\mathbf{1 8}^{\mathbf{a}}$ reunião geral do PIBID \\
\hline Data da Atividade: & 03 de março de 2015 \\
\hline Documentado em: & 1 $^{\text {a }}$ Leitura em 04 de março de 2015 (Memorista 1) \\
& 2 $^{\text {a }}$ Leitura em 06 de março de 2015 (Memorista 2) \\
& $3^{\text {a }}$ Leitura em 10 de março de 2015 (Memorista 3) \\
\hline Presentes: & Relação dos presentes na reunião. \\
\hline
\end{tabular}

Tópicos discutidos:

- Informes gerais;

- Cronograma das atividades para 2015;

- Organização dos grupos de trabalho.

Fonte: os autores.

Conforme apresentado na Figura 1, antes de iniciar a produção da memória, são preenchidos alguns dados como o número da reunião na qual a coleta foi realizada, a data, o nome dos memoristas e o nome de todos os presentes. Na linha "documentado em" os nomes dos três memoristas responsáveis pelo registro são inseridos após a data na qual a redação foi produzida; e as cores diferentes são utilizadas, a fim de diferenciar a inserção de cada um dos memoristas no corpo do documento. 
Para os objetivos pretendidos neste artigo foram analisadas dezenove memórias (dezesseis relativas ao ano de 2014 e três referentes ao ano de 2015). $\mathrm{Na}$ produção das memórias, o grupo possuía dois memoristas fixos que sempre faziam a primeira e a segunda leituras e, no início da reunião, elegia-se um terceiro bolsista para ajudar na produção.

As reuniões com todo o grupo ocorriam quinzenalmente e, nessas, os coordenadores passavam alguns informes gerais, datas de eventos, apresentavam a memória da reunião anterior, entre outras informações relevantes. Havia reuniões em que os bolsistas apresentavam seminários, abordando temáticas relativas ao ensino das Ciências, com posterior discussão. Os artigos eram selecionados pelos coordenadores e disponibilizados ao grupo para uma leitura prévia. Ao término das reuniões os bolsistas discutiam, com seus respectivos supervisores, questões referentes ao desenvolvimento das SE nas escolas e, durante as reuniões, os memoristas anotavam as discussões.

Buscando atingir os objetivos propostos, utilizamos como metodologia de análise e interpretação do corpus, a Análise de Conteúdo, fundamentada principalmente nas ideias de Bardin (2011). O primeiro movimento analítico foi olhar para as memórias buscando registros de como este instrumento metodológico contribuiu para a organização e sistematização do grupo. $\mathrm{Na}$ sequência, as memórias foram novamente analisadas, a fim de esboçar o perfil do grupo PIBID/Química. Por conseguinte, algumas falas dos participantes que apresentavam ideias convergentes foram separadas e agrupadas em categorias. Desses agrupamentos, foram criadas categorias emergentes, cada qual com sua descrição. As categorias, seguidas de suas interpretações, revelam compreensões mais aprofundadas acerca do fenômeno investigado.

Para identificar as memórias e os participantes, utilizamos códigos, conforme descrição a seguir: $\mathrm{M}$ é a codificação utilizada para memórias (M1= memória $1, \mathrm{M} 2=$ memória 2 e assim por diante); $\mathrm{C}$ é a sigla utilizada para coordenador de área $(\mathrm{C} 1=$ coordenador $1, \mathrm{C} 2=$ coordenador 2$)$; $\mathrm{S}$ é a sigla para o supervisor ( $\mathrm{S} 1=$ supervisor $1, \mathrm{~S} 2=$ supervisor 2 , e assim por diante); $\mathrm{U}$ é a sigla utilizada para professor universitário colaborador no projeto (U1= professor universitário 1, U2= professor universitário 2); do mesmo modo, B é a sigla referente aos bolsistas.

\section{APRESENTANDO OS RESULTADOS E A DISCUSSÃO}

No que diz respeito às potencialidades e contribuições das memórias para a organização e sistematização do grupo PIBID/Química encontramos alguns relatos que mencionam a utilização das memórias durante as reuniões. Elencamos algumas falas dos participantes.

Durante a apresentação de um seminário que discutia sobre os embasamentos teóricos que fundamentam as memórias, ${ }^{2}$ destacamos a fala de um coordenador:

Gostei da fala do PU1 na apresentação do artigo quando ele comentou que na memória ficam os "acordos" decididos em reunião. (C1; M15) 
O coordenador destaca que os acordos, regras e decisões do grupo ficam registrados nas memórias e esses devem ser seguidos por todos os participantes. Como a memória é disponibilizada a todo o grupo, quando um dos membros se ausenta de alguma reunião, esse tem acesso à memória que contém todas as informações discutidas, não havendo justificativa de desconhecimento dos acordos.

Destacamos outras falas que evidenciam a importância das memórias para consultas posteriores. O C1 questiona um dos bolsistas sobre quais grupos ficaram de entregar os materiais desenvolvidos ao longo do semestre e o bolsista responde:

\section{Preciso pegar na memória. (B36; M14)}

Em outra reunião, o C1 solicita novamente aos bolsistas que realizem a entrega dos materiais e comenta que, em alguma das memórias, há uma relação dos bolsistas responsáveis por recebê-los, então, o B36, um dos memoristas fixos, afirma:

A relação com os nomes está na memória 7 . (B36; M9)

Os materiais a que nos referimos nos trechos anteriores são slides, textos, fotos, arquivos que compõem as SE desenvolvidas nas escolas. Essas foram solicitadas pelo C1 para serem inseridas no relatório parcial a ser entregue para a CAPES.

Diante dos registros acima apresentados, as memórias permitem retomar o que foi discutido ou acordado nas reuniões ou encontros, possibilitando "certo avanço nas discussões e no controle dos encaminhamentos que proporcionam o amadurecimento e o entrosamento dos investigados e dos pesquisadores, quanto aos objetivos a serem alcançados pelo grupo" (PASSOS et al., 2008, s/p).

Assim como mencionado por Passos et al. (2008) nosso objetivo ao inserir as memórias no grupo também consistia no controle dos encaminhamentos, contribuindo para a organização e sistematização do grupo PIBID/Química. No entanto, ao fazer a leitura dos registros presentes nas memórias analisadas observamos outras possibilidades de uso deste instrumento metodológico, conforme destaca o B21.

O trabalho das memórias é legal, quando a gente vai para a escola a gente escolhe alguém para anotar todas as falas e assim a gente faz os trabalhos em torno dessas anotações. (B21; M15)

As memórias, a priori, eram utilizadas apenas nas reuniões quinzenais do grupo, mas ao perceber a importância da utilização das memórias bem como sua utilidade para coletar dados, o bolsista expande a ideia e começa a utilizá-la também no colégio em que desenvolve suas atividades. Essa coleta de dados possibilita registros que servem para a elaboração de trabalhos para eventos, incentivando os bolsistas a realizarem pesquisas em sala de aula.

Ao ser utilizada nesse contexto, "essa forma de coleta permite ao pesquisador o controle sobre os seus dados desde o início, o controle da própria pesquisa por meio do registro dos dados e, ainda, o delineamento intensivo do próprio trabalho" (PASSOS et al., 2007, s/p). 
A partir desse movimento inicial constatou-se a capacidade de utilizar as memórias para apoiar a construção de um esboço do perfil do grupo PIBID/ Química. Nesse contexto de investigação, os relatos dos participantes foram analisados e classificados em seis categorias não excludentes, descritas no Quadro 1.

Quadro 1. Categorias emergentes e sua descrição

\begin{tabular}{|c|c|}
\hline Categorias & Descrição \\
\hline $\begin{array}{l}\text { 01) Estudo de textos, referencial } \\
\text { teórico e seminários }\end{array}$ & $\begin{array}{l}\text { Refere-se às discussões do grupo a respeito } \\
\text { das apresentações dos seminários e estudo } \\
\text { de referenciais teóricos. }\end{array}$ \\
\hline 02) Relatos de experiências do PIBID & $\begin{array}{l}\text { Relatos de experiências vivenciadas pelos bolsistas } \\
\text { e pelos supervisores relacionadas ao PIBID/ } \\
\text { Química que descrevem o que a participação no } \\
\text { grupo acrescentou na sua formação. }\end{array}$ \\
\hline 03) Estratégias de ensino ${ }^{3}$ & $\begin{array}{l}\text { Discussões sobre estratégias de ensino e } \\
\text { diferentes metodologias que podem ser } \\
\text { utilizadas em sala de aula. }\end{array}$ \\
\hline 04) Eventos e produção acadêmica & $\begin{array}{l}\text { Discussões relacionadas à produção de artigos } \\
\text { científicos e participação de bolsistas } \\
\text { e supervisores em eventos da área. }\end{array}$ \\
\hline 05) Questões de sala de aula & $\begin{array}{l}\text { Questões que abordam aspectos da sala de } \\
\text { aula fora do contexto do PIBID. }\end{array}$ \\
\hline $\begin{array}{l}\text { 06) Impactos do PIBID na } \\
\text { comunidade escolar }\end{array}$ & $\begin{array}{l}\text { Resultados da ação dos bolsistas nas escolas } \\
\text { atendidas pelo projeto. }\end{array}$ \\
\hline
\end{tabular}

Fonte: os autores.

A seguir apresentamos algumas falas dos participantes que se encontram classificadas em cada uma das categorias descritas no Quadro 1.

Para a primeira categoria - Estudo de textos, referencial teórico e seminários - selecionamos alguns relatos.

Em uma reunião na qual se discutia um texto sobre as teorias da aprendizagem, destacamos a seguinte fala:

Ah! Eu não conhecia as ideias de Piaget. Eu procurei mais sobre a vida dele, como ele começou seus trabalhos. (B5; M11)

O B5 apresentou um seminário de um texto que discutia as ideias de Piaget em situações de sala de aula. ${ }^{4}$ Durante a apresentação, ele comenta que buscou outros textos de apoio, a fim de compreender melhor o conteúdo do artigo estudado, uma vez que ainda não havia tido contato com esse referencial, 
visto que na grade curricular do curso de licenciatura em Química as disciplinas responsáveis por essa discussão são ofertadas a partir do terceiro ano e o bolsista se encontrava no segundo ano da graduação.

Uma das professoras supervisoras, durante a discussão de um artigo, sugere a leitura de textos que abordam as ideias de Vygotsky, conforme relato:

Quero falar sobre a reformulação do Projeto Politico Pedagógico do colégio aplicação, e sugiro um seminário sobre Vygotsky. (PS6; M12)

O Projeto Político Pedagógico do colégio Aplicação, um dos colégios atendidos pelo projeto, é fundamentado nos estudos de Vygotsky, nesse sentido, o supervisor sentiu necessidade de discutir esse referencial, uma vez que é importante que os bolsistas conheçam os referenciais que fundamentam os documentos e as propostas oficiais das escolas onde atuam.

Assim como reforça o supervisor, Tardif (2014) destaca o papel dos saberes curriculares na formação docente. De acordo com o autor, "esses saberes correspondem aos discursos, objetivos, conteúdos e métodos a partir dos quais a instituição escolar categoriza e apresenta os saberes sociais por ela definidos e selecionados [...] apresentando-se concretamente sob a forma de programas escolares" (p. 38). Assim, juntamente com os outros saberes inerentes à prática do professor (experienciais, pedagógicos e disciplinares), os saberes curriculares devem ser problematizados de maneira articulada na formação do professor.

Com base na solicitação do supervisor, o coordenador selecionou um texto que trazia as ideias de Vygotsky vinculadas às atividades experimentais, ${ }^{5} \mathrm{com}$ o propósito de contribuir com as atividades do projeto.

Selecionamos um texto bem interessante que fala sobre a experimentação com as ideias do Vygotsky, e en penso que essas discussões ajudam na elaboração das situaçoes de estudo e em seu aprimoramento. (C1; M14)

A discussão desse referencial teórico, além de contribuir para que os bolsistas compreendessem os fundamentos das propostas pedagógicas vigentes nas escolas, na visão do coordenador, possibilitava embasar teoricamente a elaboração das SE, referencial utilizado pelo PIBID/Química. Isso porque a elaboração da SE fundamenta-se na teoria sócio-histórico-cultural de Vygotsky, segundo a qual devem ser considerados elementos do dia a dia dos estudantes, ressaltando a necessidade de mediação de conceitos científicos. "Isso no entendimento de que essas vivências e as relações que o aluno estabelece com seu meio são importantes na construção do conhecimento que possibilita a formação das funções psicológicas superiores, como a capacidade de generalizar e de abstrair" (SANGIOGO et al., 2013, p.38).

Para a segunda categoria - Relatos de experiências do PIBID - destacamos uma fala coletada durante uma reunião do grupo na qual foi discutido um texto sobre Situações de Estudo, ${ }^{6}$ proposta do grupo PIBID:

Eu tentei relacionar as propostas trabalhadas em anos anteriores com as situações de estudo. (B23; M3) 
O bolsista, que está no projeto desde o primeiro edital, busca identificar semelhanças e diferenças entre as propostas já trabalhadas no grupo. No primeiro edital (vigência do projeto 2010-2013) o grupo elaborava as atividades tendo como fundamentação as Unidades de Aprendizagem (GALIAZZI; GARCIA; LINDEMANN, 2004). No Edital de 2011 (vigência do projeto 2011-2013), foram utilizadas as fichas de aula dialogadas (FARIA et al., 2012), proposta elaborada pelos coordenadores do grupo com base em referenciais teórico-metodológicos da área. Já no último edital (vigência do projeto 2014-2016) o grupo elaborava e desenvolvia Situações de Estudo (MALDANER; ZANON, 2001).

Classificamos esse relato na segunda categoria, uma vez que o bolsista tenta buscar aproximações teórico-metodológicas entre as distintas abordagens adotadas no projeto. Ao buscar relações entre os referenciais estudados, o bolsista revela partir de conhecimentos prévios, adquiridos por meio das experiências vivenciadas no projeto, a fim de estabelecer novas articulações entre as abordagens propostas. Por esse motivo, essa fala também pode ser classificada na categoria 1.

Em outra reunião do grupo em que os resultados das atividades desenvolvidas nas escolas estavam sendo apresentados, destacamos o seguinte relato de um bolsista:

Uma coisa legal é que eu aprendi a trabalhar em equipe. O B21 entende bastante, ajudou muito (B6; M16)

O bolsista relata a importância do convívio com licenciandos que estão há mais tempo no projeto e em anos finais da graduação, evidenciando a troca de experiências, e destaca como essencial o trabalho em equipe para o desenvolvimento das atividades, pois, segundo o relato, sua participação no PIBID possibilitou esse aprendizado.

O PS4, ao relatar os resultados das atividades desenvolvidas pelo grupo, afirma que a aprendizagem da docência não se restringe à sala de aula, mas está também nas relações estabelecidas com os demais membros da comunidade escolar.

Acho que os bolsistas puderam conhecer melhor o cotidiano da escola. Conversar com os diretores, pedagogos. Conhecer a relação entre professor e aluno. (PS4; M16)

Analisando a fala do supervisor nota-se o significado atribuído ao ambiente escolar como local de aprendizagem da docência. Nesse sentido, as atividades desenvolvidas pelo PIBID inserem os bolsistas nesse contexto, seu futuro local de trabalho, com a finalidade de colocá-los em contato com os sujeitos que participam da dinâmica escolar.

Durante uma reunião, um bolsista relata suas expectativas e as confronta com as experiências vivenciadas ao desenvolver as atividades no projeto:

[...] eu gostei muito de desenvolver as atividades. Fiz amizade com os alunos e me senti muito solto dentro da sala de aula. Eu não sabia como ia ser, mas me senti bem vindo, senti que eles gostaram. Eu me descobri lá. (B28; M16)

O B28 menciona seus anseios iniciais com relação à atuação docente, ao relacionamento com os alunos e ao seu primeiro contato com o ambiente escolar, 
demonstrando insegurança. Contudo, após sua inserção nas atividades do projeto mostra-se motivado e começa a se identificar no papel de docente.

De acordo com Pimenta (2012) a identidade do professor está muito ligada ao significado social e a sua manifestação na prática em sala de aula. Para a autora:

Uma identidade profissional se constrói, pois, a partir da significação social da profissão; da revisão constante dos significados sociais; das tradições. Mas também da reafirmação das práticas consagradas culturalmente e que permanecem significativas (PIMENTA, 2012, p. 20).

A construção da identidade profissional se dá em uma diversidade de contextos a partir dos quais os licenciandos estruturam ideias, crenças e valores, estabelecendo suas teorias sobre ensinar e aprender Ciências. Dessa forma, esses contextos fornecem uma oportunidade para reflexão e aprendizagem da docência.

Para a categoria 3 - Estratégias de ensino - selecionamos algumas falas. Durante o estudo de um texto que discutia a utilização de diferentes estratégias de ensino nas SE, 7 o PS3 expõe sua opinião sobre como essas estratégias devem ser utilizadas.

Eu entendo que a estratégia de ensino deve ser utilizada de forma a fazer o aluno participar da aula, que ele entenda o que ele está fazendo, que ele tenha dúvidas para pesquisar, perguntar, sugerir alguns temas para assim trabalhar com o conceito. (PS3; M5)

O supervisor destaca que as estratégias de ensino devem ser utilizadas em momentos que contribuam com a aprendizagem dos alunos, favorecendo a motivação, a ressignificação dos conceitos. Acrescenta que essas devem estar atreladas ao planejamento de ensino do professor para que não sejam percebidas pelos alunos como atividades desvinculadas dos objetivos da aula.

Ainda discutindo sobre as estratégias de ensino, iniciou-se um debate a respeito da experimentação, a partir do qual surgiram várias ideias. O PS1 relatou que tinha certa resistência em levar os alunos ao laboratório e que, quando o fazia, antes finalizava o conteúdo em sala de aula.

Eu era muito resistente a essa estratégia de ir ao laboratório, eu sempre terminava o conteúdo para depois ir ao laboratório. Então eu mostrava que o que a gente viu na aula estava ali. Isso, na maioria das vezes não funciona. (PS1; M5)

O relato do supervisor corrobora um pensamento muito comum entre os professores de Ciências de que as aulas práticas servem para comprovar a teoria, devendo, portanto, serem realizadas após as aulas teóricas. Porém, com as discussões realizadas no PIBID, o supervisor repensa suas ideias sobre o momento de realização das atividades experimentais e sobre a função da experimentação como estratégia de ensino nas aulas de Química.

No relato a seguir, o PS5 apresenta outra ideia sobre a função da experimentação.

Eu já vejo a experimentação como despertar a curiosidade, interesse pela quimica, não necessariamente comprovar a teoria. (PS5; M5) 
Embora o PS5 afirme que a experimentação não tenha como função a comprovação da teoria na prática, esse ainda apresenta uma visão bastante simplista em relação à utilização dessa estratégia: o objetivo seria despertar o interesse e a curiosidade dos alunos. Ainda a respeito da discussão sobre experimentação, destacamos a fala do PS4.

Na minha opinião, eu sei que tem autores que defendem isso, mas esse negócio de usar materiais de baixo custo para fazer experimentos, eu não concordo. (PS4; M5)

Assim como os demais supervisores, o PS4 reforça uma visão simplista da função da experimentação no ensino de química, ressaltando sua rejeição ao uso de materiais de baixo custo nas atividades experimentais.

Vários autores (BARBERA; VALDEZ, 1994; GIORDAN, 1999; THOMAZ, 2000; TEÓFILO; BRAATHEN; RUBINGER, 2002; GUIMARÃES, 2009; AMAURO; SOUZA; MORI, 2015) ressaltam que um número expressivo de professores de Ciências ainda apresenta visões simplistas acerca dos objetivos das atividades experimentais, visões essas nas quais tais atividades assumiriam a função de verificação de teorias ou de descoberta de teorias e/ou simplesmente de motivação dos estudantes - despertar o interesse e a curiosidade a partir dos fenômenos observados nos experimentos.

Outro fator importante, destacado por'Teófilo, Braathen e Rubinger (2002), refere-se à crença de alguns professores de que o desenvolvimento de atividades experimentais na Educação Básica exige um laboratório equipado, com reagentes e vidrarias específicos, concepção corroborada pela fala de PS4. Segundo os autores, é necessário que o professor considere a utilização de materiais alternativos e de baixo custo na proposição desse tipo de atividade, uma vez que isso possibilita que os estudantes aprendam que "[...] a Química extrapola as paredes do laboratório e está presente em suas casas e em outros setores da sociedade" (TEÓFILO; BRAATHEN; RUBINGER, 2002, p. 44).

Todas as falas que citamos anteriormente foram retiradas de uma mesma reunião (memória 5), na qual tivemos uma longa discussão acerca da experimentação nas aulas de Química. Porém, outras estratégias de ensino aparecem quando analisamos outras memórias e são a elas que dirigimos, em seguida, nossa atenção.

Ao discutir sobre a elaboração das atividades os bolsistas e os supervisores mencionam outras estratégias que podem ser utilizadas no desenvolvimento das SE - como a leitura e discussão de textos, softwares, trabalhos em grupo, lista de exercícios -, e que visam contemplar os objetivos de cada uma das etapas.

Por que vocês não utilizam um texto que relate sobre o funcionamento de uma pilha? (B36; M18)

E com o software que o PU2 passou, o Equil, ajudou e muito para que eles entendessem o conteúdo, tornou-se mais palpável. (B28; M16)

Uma estratégia que eu uso para que os alunos estudem é trabalhar com texto e com lista de exercícios. Eu costumo reuni-los em grupos para que eles façam as atividades sozinhos. (PS4; M5) 
A construção do perfil de um grupo PIBID/Química a partir das memórias como um instrumento de coleta de dados

De acordo com os pressupostos que fundamentam as SE desenvolvidas pelo grupo, a segunda etapa - primeira elaboração:

[...] remete para atividades que envolvem, especialmente, textos de aprofundamento sobre as circunstâncias que foram apresentadas na primeira etapa - problematização. É por meio dessas atividades que os estudantes vão ter o primeiro contato com conhecimentos científicos para além da palavra representativa de um determinado conceito. Esse primeiro contato com a palavra representativa de um conceito, num determinado contexto, é realizado mediante a orientação do professor em diversas atividades (GEHLEN; MALDANER; DELIZOICOV, 2012, p.10).

Nesse sentido, as discussões acerca das diferentes estratégias que podem ser utilizadas na elaboração e no desenvolvimento das SE, principalmente na segunda etapa, possibilitam a sustentação das atividades propostas, por meio das quais "buscam-se novos contextos, já mais distantes do contexto inicial em que o conceito foi introduzido pela primeira vez. Com isso os significados iniciais podem evoluir" (GEHLEN; MALDANER; DELIZOICOV, 2012, p.12).

Para a categoria 4 - Eventos e produção acadêmica - elencamos algumas falas dos participantes. Os relatos classificados nessa categoria trazem informes sobre os eventos, resultados de avaliação dos trabalhos submetidos e feedback dos bolsistas após a participação.

Vai acontecer o II Seminário Estadual do PIBID nos dias 23 e 24 de Outubro em Foz do Iguaçu. (C2; M11)

Nós estamos extremamente felizes, praticamente todos os trabalhos enviados por nosso grupo foram aprovados [...] mais de 60\% dos trabalbos foram aprovados sem que houvesse a necessidade de correção e inclusive com observações positivas dos corretores. (C1; M8)

Achei que como são todos os PIBID's o evento fica perdido porque os focos são muito diferentes. As apresentações eram mais de outras áreas e por isso não geram discussões. Uma coisa que percebi é que vários grupos não desenvolvem pesquisas no PIBID. (B10; M15)

No primeiro relato, o C2 informa aos demais participantes que acontecerá um evento e que os bolsistas deverão participar. No segundo, o C1 comenta sobre o resultado positivo em relação à produção de trabalhos do grupo submetidos a um evento da área, destacando a importância da pesquisa em sala de aula na formação dos bolsistas, fato esse também ressaltado pelo B10, ao relatar sobre sua participação em um evento que reunia grupos PIBID de diferentes áreas.

De acordo com Pena e Ribeiro-Filho (2007), a produção da pesquisa em Ensino de Ciências vem crescendo consideravelmente, evidenciando a ampliação do número de experiências que incorporam os resultados das pesquisas do campo educacional, assim como as inúmeras possibilidades de divulgação e disseminação dos resultados em congressos e periódicos da área. Nesse contexto, autores como Galiazzi (2003) e Delizoicov (2005) enfatizam a relevância do futuro professor participar da pesquisa em todo o processo, como condição necessária e desejável à 
sua formação, aproximando, dessa forma, os resultados das pesquisas em Ensino de Ciências ao Ensino de Ciências.

Para a categoria 5 - Questões de sala de aula - elencamos algumas falas dos participantes que relatam experiências e refletem sobre situações de sala de aula desvinculadas do contexto do PIBID.

Mesmo a turma sendo bem heterogênea, o trabalho fuí. Porém, naquela turma eu explicava e propunha um problema para ser resolvido em pequenos grupos. (PS1; M14)

$\mathrm{Na}$ fala citada, o PS1 comenta características de uma determinada turma na qual lecionava. O supervisor destaca que a escolha da estratégia depende do perfil da turma. No caso mencionado, a partir de sua experiência, o professor faz uso do trabalho em grupo, visto que essa se mostrou uma estratégia eficaz para o contexto. Esse relato também se enquadra na categoria 3, uma vez o supervisor menciona o uso de uma estratégia específica com a turma em questão.

$\mathrm{Na}$ fala a seguir, o PS3 reflete acerca da rotina da sala de aula e sua influência na aprendizagem.

Na sala de aula sentar um atrás do outro todo dia, todo dia, será que eles estão aprendendo mesmo? Será que vai ter rendimento até o final do ano. (PS3, M14)

Além da disposição espacial destacada pelo supervisor, outros aspectos podem ser pensados a partir desse relato. Ao refletir sobre essas questões, o supervisor demonstra preocupação com a rotina da sala de aula, ou seja, com a utilização da mesma sequência dos conteúdos, do mesmo exercício, independente da turma e do perfil dos alunos, evidenciando a influência desses fatores nos processos de ensino e de aprendizagem.

No relato a seguir o PS6 menciona uma conversa informal com dois de seus alunos acerca de um assunto extraclasse, destacando o interesse dos estudantes pela busca de mais informações.

Entre uma aula e outra dois alunos vieram me perguntar sobre assuntos de astronomia e depois que en sai os dois continuaram conversando. Foram eles quem pesquisaram, trouxeram a dúvida. (PS6; M7)

A fala anterior aconteceu em uma reunião na qual se discutia um artigo sobre aprendizado científico no cotidiano. ${ }^{8} \mathrm{O}$ supervisor ressalta a importância dessas conversas com os alunos fora da sala de aula, motivando-os e incentivandoos a buscar o conhecimento para além do que é discutido no currículo escolar.

Como observado, pode-se notar que as falas citadas nessa categoria foram apenas de professores supervisores, visto que nela se enquadram falas que abordam aspectos da sala de aula fora do contexto PIBID, ou seja, por se tratar do ambiente de trabalho dos supervisores era esperado que houvesse relatos baseados em suas experiências cotidianas, uma vez que essa troca de experiências contribui na formação docente dos bolsistas do PIBID.

As colocações dos supervisores, citadas nessa categoria, corroboram um dos objetivos do PIBID: “incentivar escolas públicas de educação básica, mobilizando 
seus professores como coformadores dos futuros docentes e tornando-os protagonistas nos processos de formação inicial para o magistério” (BRASIL, 2010). Para Tardif (2014, p. 289),

[...] professores de profissão [...] se tornam, a partir de então, verdadeiros atores da formação dos futuros docentes. Ao passo que, tradicionalmente, os professores de profissão se situavam na periferia da formação inicial, tenta-se, hoje, dar-lhes um espaço mais importante. Em última instância, tais como os universitários, os professores se tornam formadores e são integrados nas atividades de formação dos futuros professores (TARDIF, 2014, p. 289).

Nesse sentido, esse ambiente de discussão de problemáticas relacionadas à formação de professores, tendo como objeto de estudo as teorias dos próprios professores, possibilita ao supervisor clareza em relação à sua responsabilidade no programa: levar o licenciando a refletir sobre a ação do professor e sobre sua própria prática. Isso porque, de acordo com Galiazzi (2003), espaços de reflexão coletivos podem proporcionar melhores perspectivas quanto à formação do professor, possibilitando a discussão sobre as dificuldades na ação docente e as possíveis mudanças na prática diária do professor.

Para a categoria 6 - Impactos do PIBID na comunidade escolar selecionamos algumas falas.

As crianças vão até a minha sala e perguntam quando os bolsistas vão à escola, os outros professores do colégio também fazem a mesma pergunta. (PS3; M15)

Os alunos prestam atenção no trabalho dos bolsistas, mudam até a postura quando o pessoal chega. (PS2; M15)

[...] as atividades foram satisfatórias tanto para os bolsistas, como para mim enquanto supervisor e para a escola. (PS2; M16)

Como resultado das ações do PIBID nas escolas participantes, os supervisores destacam que os ganhos com a participação no projeto não se restringem apenas aos bolsistas e supervisores, sujeitos ligados diretamente ao projeto, mas a todo contexto escolar, agregando conhecimento a todos os participantes, o que vai ao encontro dos objetivos do programa. Os estudantes ficam motivados com as atividades desenvolvidas pelos bolsistas, interagindo e participando mais das aulas. Com relação aos demais professores das escolas, esses demonstram curiosidade e interesse pelas ações propostas pelo grupo, uma vez que presenciam os resultados alcançados pelo projeto.

Corroborando os relatos expostos anteriormente, Neitzel, Ferreira e Costa (2013) apontam alguns impactos que o PIBID traz à realidade das escolas atendidas pelo programa, destacando o posicionamento de gestores e estudantes da Educação Básica:

[...] aos gestores de escolas públicas: mostram-se mais abertos ao diálogo com o público 
externo, evidenciando-se menos receio em discutir as situações de conflito da escola; abertura para o desenvolvimento de ações inovadoras e flexibilização do planejamento, da rotina, dos horários e das regras preestabelecidas; há grande movimentação das escolas parceiras em torno de projetos, eventos e feiras facilitando o processo; buscam a participação da família nos processos educativos; e valorizam os projetos desenvolvidos pela equipe. [...] aos alunos: são contemplados com estratégias de ensino diversificadas, o que aumenta suas possibilidades de ensino e aprendizagem; há um movimento dos alunos que evidencia que eles podem ser os protagonistas de sua aprendizagem; participam das atividades propostas, mesmo daquelas oferecidas no contraturno (NEITZEL; FERREIRA; COSTA, 2013, p. 116-117).

Nesse sentido, Nunes (2014) afirma que o impacto do PIBID na comunidade escolar extrapola o espaço de sala de aula de uma dada disciplina, "possibilitando uma transformação efetiva no ambiente escolar como um todo. São as escolas que recebem o PIBID - e não disciplinas que recebem cada bolsista -, o que permite a integração entre os diferentes atores envolvidos" (NUNES, 2014, s/p).

Mais especificamente em relação à fala do PS2 na M16, essa também pode ser classificada na categoria 2, visto que o supervisor descreve as aprendizagens construídas ao longo do projeto, ressaltando que a participação no grupo contribuiu para a sua formação.

O Quadro 2 apresenta a frequência com que cada categoria aparece nas memórias analisadas.

Quadro 2. Frequência das categorias nas memórias analisadas

\begin{tabular}{|c|c|c|c|c|c|c|c|c|c|c|c|c|c|c|c|c|c|c|c|c|}
\hline $\begin{array}{c}\text { Categorias*I } \\
\text { Memórias }\end{array}$ & M1 & M2 & M3 & M4 & M5 & M6 & M7 & M8 & M9 & M10 & M11 & M12 & M13 & M14 & M15 & M16 & M17 & M18 & M19 & T \\
\hline 1 & 3 & - & 2 & 2 & 3 & - & 2 & - & - & 3 & 1 & 2 & - & 5 & - & - & 11 & 17 & 8 & 59 \\
\hline 2 & - & 2 & 5 & 2 & - & 3 & 2 & 2 & 1 & - & 2 & 4 & - & 1 & 1 & 16 & - & 7 & - & 48 \\
\hline 3 & 2 & - & 2 & 2 & 12 & 4 & 2 & 2 & 1 & 10 & 2 & 1 & - & 5 & - & - & - & 13 & - & 58 \\
\hline 4 & 4 & 4 & - & - & - & - & 2 & 2 & 2 & 4 & 1 & 5 & 1 & 2 & 13 & 2 & 1 & - & 1 & 40 \\
\hline 5 & - & - & 1 & 3 & 5 & 3 & 1 & 2 & - & - & 1 & - & 10 & 3 & - & - & 2 & 1 & - & 32 \\
\hline 6 & - & - & - & - & - & - & - & - & - & - & - & - & - & 1 & 2 & 3 & - & - & - & 6 \\
\hline
\end{tabular}

* 1. Estudo de textos e referenciais teóricos; 2. Relatos de experiência no PIBID; 3. Estratégias de ensino; 4. Eventos e produção acadêmica; 5. Questões de sala de aula; 6 . Impactos do PIBID na comunidade escolar.

Fonte: os autores.

Mediante a análise do Quadro 2, observa-se que, embora vários assuntos sejam discutidos em uma mesma reunião (por exemplo, a M14 contempla todas as categorias), em uma análise mais ampla percebe-se que o grupo acaba por priorizar alguns tópicos, possibilitando que um perfil seja traçado.

O estudo de textos e referenciais teóricos (categoria 1) é o tópico que apresenta maior incidência de falas, seguido de estratégias de ensino (categoria 3); relatos de experiência no PIBID (categoria 2) e eventos e produção acadêmica (categoria 4). 
Como mencionado, na maioria das reuniões quinzenais havia apresentações de seminários envolvendo temas voltados para a Educação Científica, o que justifica a grande quantidade de relatos classificados na categoria 1. Muitos dos textos trabalhados contemplavam estratégias de ensino, na busca por instrumentalizar os bolsistas na elaboração das SE que seriam desenvolvidas nas escolas participantes. Nesse sentido, ao estudar os referenciais teóricos (categoria 1) e as estratégias de ensino (categoria 3), os bolsistas buscavam propor atividades fundamentadas para essas discussões que, ao serem desenvolvidas nas escolas, geravam relatos de experiências do PIBID (categoria 2), outra categoria com bastante representatividade.

Com relação à categoria "eventos e produção acadêmica" (categoria 4), também com um número expressivo de falas, essa pode ser justificada pelo fato de que, ao realizar estudo de referenciais teóricos simultaneamente ao desenvolvimento das SE nas escolas, os bolsistas são levados a realizar pesquisas em sala de aula, uma vez que esses referenciais sustentam a metodologia de coleta de dados e de análises, possibilitando que trabalhos científicos sejam elaborados e apresentados em eventos.

Considerando a classificação das falas nas respectivas categorias, pode-se traçar um perfil do grupo, que ressalta uma preocupação com uma formação teórica consistente aliada a uma prática docente reflexiva, o que proporciona aos participantes do grupo perceberem a sala de aula também como um ambiente de pesquisa.

Esse perfil exposto a partir da análise das memórias constituídas no grupo ratifica o que afirma Stanzani (2012). Segundo o autor, o PIBID surge fundamentado nos resultados das pesquisas, como uma forma de suprir as lacunas deixadas no processo formativo, como: a dicotomia entre teoria e prática; a desarticulação entre ensino, pesquisa e extensão; a não utilização da pesquisa como princípio formativo. Essa experiência formativa possibilita aos estudantes das licenciaturas melhores perspectivas quanto à profissão docente.

No que diz respeito aos impactos do PIBID na comunidade escolar (categoria 6), essa foi a categoria que apresentou a menor incidência de falas - concentradas nas três últimas reuniões de 2014. Por se tratar de relatos que abordam os resultados das ações dos bolsistas nas escolas atendidas pelo projeto, é de se esperar que esses apareçam nas reuniões finais do grupo, as quais priorizam discussões sobre as implicações das atividades desenvolvidas na comunidade escolar.

A categoria 5 - Questões de sala de aula - faz menção a questões que abordam aspectos da sala de aula fora do contexto do PIBID. A maioria das falas classificadas nessa categoria são dos professores supervisores que relatam experiências, inquietações, dúvidas e certezas advindas da sua vivência em sala de aula. Pensando que essa troca e compartilhamento de ideias é importante para a formação dos futuros professores, uma vez que os supervisores, por estarem há algum tempo lecionando, possuem conhecimento prático acerca da complexidade do contexto escolar, torna-se fundamental que esse conhecimento seja integrado às discussões teóricas (categoria 1) que sustentam a atividade docente, categoria de maior incidência nas memórias.

Esse conhecimento prático dos professores, denominado por Gauthier e colaboradores (1998) como saber experiencial, corresponde aos conhecimentos produzidos pelo professor em meio às experiências vividas; são elaborados ao longo do tempo e restritos à sala de aula. 
Além das categorias acima mencionadas que predominaram ao longo da execução do projeto as quais possibilitaram mapear os principais enfoques dados nas reuniões, buscamos também relacionar a frequência de participação dos membros do grupo aos eixos temáticos tanto para os professores supervisores como para os bolsistas de iniciação à docência.?

Ao analisar os registros nas memórias constatam-se distintas frequências de participação ${ }^{10}$ entre os supervisores. Há os que interagem com mais regularidade, como o PS5, o PS3 e o PS4 e os que se expressam pouco durante as reuniões, não exteriorizando suas opiniões, como é o caso do PS2.

A fim de aprofundar a análise fez-se uma busca dos temas mais mencionados pelos supervisores. Nesse levantamento evidenciamos que os supervisores apresentam maior participação em discussões relacionadas às categorias 5 - Questões de sala de aula - e 1 - Estudo de textos e referenciais teóricos. Durante as discussões de textos e referenciais teóricos os supervisores buscam relacionar o que está sendo discutido com aspectos vivenciados em sua prática docente, destacando a valorização do saber experiencial, fato esse que justifica a predominância das falas nas categorias mencionadas, uma vez que proporcionar esses momentos de discussão é também um dos objetivos do projeto.

Segundo Garcia (1999), o valor da experiência no ensino e na formação do professor deve estar ligado à qualidade da experiência vivida, que se adquire por meio de processos reflexivos, pois, sem a reflexão sobre a prática docente, o que acontece é a repetição de uma mesma prática não problematizada, inexistindo a aprendizagem para saber ensinar.

Assim, as discussões e reflexões realizadas nas reuniões permitem que os participantes e, nesse cenário, principalmente os supervisores, exponham suas vivências e os conhecimentos advindos da experiência, buscando problematizar tais saberes a partir dos referenciais teóricos estudados. Isso confere maior embasamento às discussões realizadas, contribuindo de maneira significativa com os processos de formação inicial e continuada de professores.

A categoria de menor destaque nas falas dos supervisores foi a categoria 4 - Eventos e produção acadêmica. Embora os supervisores contribuam na escrita dos trabalhos a serem apresentados, esses relatam, muitas vezes, não ter incentivo por parte das escolas para participarem, principalmente em eventos mais distantes, o que justifica a pouca ênfase nas discussões sobre esse tema pelos supervisores.

Conforme destacam Neitzel, Ferreira e Costa (2013), o desenvolvimento das atividades do PIBID em parceira com as escolas promove e fortalece a cultura de participação em seminários e eventos entre os membros da comunidade escolar, gestores e professores. Mesmo sendo um tema pouco recorrente na fala dos professores, percebe-se, ao longo da participação no projeto, um maior interesse dos supervisores por esse tipo de atividade, a qual visa à divulgação dos trabalhos realizados nas escolas. Porém, mesmo com o incentivo por parte dos coordenadores, entendemos que alguns obstáculos ainda precisam ser superados para que essa prática se torne intrínseca ao trabalho do professor, uma vez que as ações do PIBID buscam integrar o supervisor às pesquisas acerca da prática docente, e a participação em eventos acadêmicos faz parte desse processo. 
Quanto à frequência de participação dos bolsistas nas discussões, destacase o alto índice de interação de B9 e B10 quando comparado à reduzida participação de B4 e B40. Há também aqueles que não se manifestam ao longo das reuniões, como B7 e B16.

Com relação aos temas mais discutidos pelos bolsistas, destacam-se as categorias 4 - Eventos e produção acadêmica -, 1 - Estudo de textos e referenciais teóricos - e 3 - Estratégias de ensino.

Como já mencionado durante a discussão do Quadro 2, pode-se estabelecer uma correlação entre as elevadas frequências de participação dos bolsistas nas categorias 1, 3 e 4, uma vez que a elaboração dos trabalhos apresentados em eventos decorre dos resultados alcançados nas ações de intervenção, as quais se fundamentam nos referenciais estudados ao longo das reuniões.

No que diz respeito à categoria de reduzida participação dos bolsistas destacam-se discussões cujos temas estão relacionados à categoria 6 - Impactos do PIBID na comunidade escolar. Mesmo com a inserção dos bolsistas no ambiente escolar, deve-se considerar que esses não vivenciam o dia a dia da escola de maneira acentuada, impossibilitando-os de perceber os impactos das ações do projeto na comunidade, uma vez que esses, muitas vezes só podem ser identificados a longo prazo. Há que se levar em consideração também a permanência, nem sempre contínua, dos bolsistas no projeto.

\section{CONSIDERACְÕES FINAIS}

Uma das ações do grupo PIBID/Química investigado consiste em reuniões nas quais há discussões e reflexões acerca de temas relativos à educação científica no contexto da Educação Básica. Nessa perspectiva, o grupo optou pelo uso das memórias como instrumento de coleta de dados, a fim de registrar e disponibilizar, de maneira ágil, os relatos a todos os participantes.

Neste artigo o foco de investigação centrou-se em discutir as potencialidades e contribuições de um instrumento de coleta de dados denominado "memórias", considerando sua capacidade de apoiar a construção de um esboço do perfil de um grupo PIBID. Vale ressaltar que, as memórias, em sua essência, não foram pensadas para este fim, entretanto, ao analisá-las nos deparamos com a possibilidade de utilizar estes registros com esse objetivo.

Nesse sentido, o primeiro movimento analítico foi olhar para as memórias buscando registros de como este instrumento metodológico contribuiu para a organização e sistematização do grupo - objetivo este mencionado no referencial de origem das memórias. Na sequência, as memórias foram novamente analisadas, a fim de esboçar o perfil do grupo PIBID/Química. Esse segundo movimento passa a conceber as memórias enquanto um instrumento que permite apoiar a construção de um esboço do perfil do grupo. Ao construir esse esboço, buscamos mapear alguns aspectos presentes nos registros analisados, os quais possibilitaram a emergência de eixos temáticos, evidenciando características que representam tal grupo.

No que diz respeito às potencialidades e contribuições das memórias, ao analisá-las em maior profundidade encontramos relatos que destacam a utilização 
das memórias durante as reuniões como uma forma de monitorar encaminhamentos, organizar e sistematizar as ações do grupo. Em várias memórias há registros de acordos, regras e decisões tomadas pelo grupo e que deviam ser postas em prática pelos participantes. Outra potencialidade das memórias, evidenciadas neste estudo, consiste na possibilidade de retomada do que foi discutido ou acordado em reuniões anteriores indicando uma gestão dos encaminhamentos e uma comunicação entre participantes, a fim de que os objetivos pretendidos pelo grupo fossem efetivados.

Para além desses fatores relacionados a organização e sistematização do grupo, ao fazer a leitura dos registros presentes nas memórias analisadas observamos outras possibilidades de uso do instrumento; os bolsistas acabavam também a utilizando como forma de registro das atividades desenvolvidas nas escolas em que desenvolviam as atividades, possibilitando realizarem pesquisas em sala de aula, ao fazerem as análises de tais registros.

Para além destes aspectos, consideramos também sua capacidade de apoiar a construção de um esboço do perfil do grupo PIBID/Química. Assim, mediante a análise das 19 memórias chegou-se à construção de seis categorias que indicam temas recorrentes nas discussões. Esse resultado apresenta que há uma diversidade de temas abordados durante as reuniões, porém, priorizam-se alguns tópicos. Os resultados evidenciam que o grupo tem como preocupação primordial possibilitar uma formação de professores fundamentada em referenciais teóricos da área, a partir da articulação entre teoria e prática, visando estabelecer um espaço de pesquisa que integre escola e universidade, bem como divulgar esses resultados em eventos científicos. Essas evidências constituem assim, o perfil do grupo.

Outra possibilidade de análise refere-se à quantificação da frequência de participação dos bolsistas e supervisores. A partir desses dados é possível detectar lacunas a serem repensadas na estruturação e organização do grupo. No caso aqui relatado, com relação aos seis supervisores, conclui-se que apenas quatro participaram de maneira efetiva das discussões propostas, contribuindo com relatos e vivências relevantes para a formação dos futuros professores e para sua própria formação.

Com relação aos bolsistas, a partir dos dados analisados, foram identificados aqueles que participaram ativamente das discussões, os que interagiam de forma fragmentada e aqueles que não participaram em nenhum momento. Considerando essa frequência de participação é possível que o coordenador do grupo reestruture ações, de modo que os bolsistas possam participar de forma mais dinâmica, o que resultaria em uma formação mais expressiva.

Esse tipo de levantamento fez com que pudéssemos identificar contribuições dos supervisores e bolsistas nas discussões, bem como os principais tópicos em que eles se manifestam, possibilitando que sejam realizadas reconduções nos assuntos abordados, a fim de inseri-los no contexto das demais discussões.

Destaca-se a possibilidade de estender essas reflexões a outros grupos de estudo e/ou pesquisa, uma vez que a utilização das memórias se mostra eficiente e ágil na identificação das potencialidades e limites do grupo, proporcionando reconduções das ações, com a finalidade de um maior envolvimento e comprometimento dos participantes. 
A construção do perfil de um grupo PIBID/Química a partir das memórias como um instrumento de coleta de dados

\section{REFERÊNCIAS}

AMAURO, N. Q.; SOUZA, P. V. T.; MORI, R. C. As funções pedagógicas da experimentação no ensino de Química. Multi-Science Journal, v. 1, n. 3, p. 17-23, 2015.

BARBERA; VALDÉS P. Investigacion y Experiências Didacticas El trabajo práctico em la ensenãnza de las ciencias: una revisión. Ensenãnza de las Ciencias, v. 14, n. 3, p. 365-379, 1994.

BARDIN. L. Análise de Conteúdo. São Paulo: Ed. Edições 70, 2011, 279p.

BRASIL. Decreto $n^{\circ} 7.219$, de 24 de junho de 2010. Dispõe sobre o Programa Institucional de Bolsa de Iniciação à Docência - PIBID e dá outras providências. Diário Oficial da União, n. 120, seção 1, p. 4-5, 2010.

BRASIL. Portaria Normativa n ${ }^{\circ}$ 38, de 12 de dezembro de 2007. Dispõe sobre o Programa Institucional de Bolsa de Iniciação à Docência - PIBID. Diário Oficial da União, n. 239, seção 1, p. 39, 2007.

DELIZOICOV, D. Resultados da pesquisa em Ensino de Ciências: comunicação ou extensão? Caderno Brasileiro de Ensino de Física, v. 22, n. 3, p. 364-378, 2005.

FARIA, W. D. B.; BIRCHES, A. C.; SILVA, C. M. C.; MOREIS, C. S.; COLOMBO, D. A.; OLIVEIRA, J. T.; SCHIMIDT, A. N. O. BROIETTI, F. C. D.; MARTORANO, S. A. A. LEITE, R. F. O PIBID/ Química UEL - Um Relato de Experiência na Escola: Abordando o Tema Radioatividade. In: XVI Encontro Nacional de Ensino de Química, 2012. Anais... XVI ENEQ, Salvador, 2012.

GALIAZZI, M. C. Educar pela pesquisa: ambiente de formação de professores de ciências. Ijuí: Ed. Unijuí, 2003.

GALIAZZI, M. C., GARCIA, F. A.; LINDEMANN, R. H. Construindo Caleidoscópios: organizando Unidades de Aprendizagem. In: MORAES, R.; MANCUSO, R. Educação em ciências: produção de currículos e formação de professores. Ijuí: UNIJUÍ, 2004, p. 65-84.

GARCIA, C. M. Formação de Professores: para uma mudança educativa. Porto: Porto Editora, 1999.

GAUTHIER, C.; MARTINEAU, S.; DESBIENS; J. F.; LIMA, F. P.; MALO, A. Por uma teoria da pedagogia: pesquisas contemporâneas sobre o saber docente. Ijuí: Ed. Unijuí, 1998, 480p.

GEHLEN, S. T.; MALDANER, O. A.; DELIZOICOV, D. Momentos pedagógicos e as Etapas de Situação de Estudo: complementaridades e contribuições para a Educação em Ciências. Ciência \& Educação, v. 18, n. 1, p. 1-22, 2012.

GUIMARÃES, C. C. Experimentação no ensino de química: caminhos e descaminhos rumo à aprendizagem significativa. Química Nova na Escola, v. 31, n. 3, p. 198-202, 2009.

GIORDAN, M. O papel da experimentação no ensino de Ciências. Química Nova da Escola, n.10, p. 43-49, 1999.

MALDANER, O. A.; ZANON, L. B. Produção coletiva e inovação curricular como mediação da formação continuada de professores. In: APED SUL, 5. Atas... 2001, p. 50. 2001.

MASETTO, M. T. Competência pedagógica do professor universitário. São Paulo: Summus, 2003.

NEITZEL, A. A.; FERREIRA, V. S.; COSTA, D. Os impactos do Pibid nas licenciaturas e na Educação Básica. Conjectura: Filosofia Educacional, v. 18, n. especial, p. 98-121, 2013. 
NERI, C. S.; PASSOS, M. M.; ARRUDA, S. M. A formação do graduando e do pós-graduando e a produção de 'memórias'. In: XIX Encontro anual de iniciação científica, 2010, Guarapuava. Anais... XIX EAIC, 2010.

NUNES, C. L. B. Interação universidade e escola: reflexões sobre os impactos do PIBID nas escolas de educação básica. In: Salão do Conhecimento - Unijui, 2014, Ijuí. Anais... XIX Jornada de Pesquisa, 2014.

OBARA, C. E.; STANZANI, E. L.; PASSOS, M. M.; ARRUDA, S. M. A coleta de dados em um museu de ciência e tecnologia e suas implicações na formação do monitor/licenciando. In: XVII Encontro Nacional de Ensino de Química, 2014, Ouro Preto - MG. Anais... XVII ENEQ, 2014.

PASSOS, M. M.; ARRUDA, S. M.; PRINS, S. A.; CARVALHO, M. A. Memórias: uma metodologia de coleta de dados - dois exemplos de aplicação. Revista Brasileira de Pesquisa em Ensino de Ciências. v.8, n. 1, 2008.

PASSOS, M. M.; PRINS, S. A.; CARVALHO, M. Al.; ARRUDA, S. M. 'Memórias': uma metodologia de coleta de dados para um trabalho com orientadores de campo no estágio supervisionado em Física. In: MORTIMER, E. F. (org.). Anais...VI Encontro Nacional de Pesquisa em Educação em Ciências. Belo Horizonte: Abrapec, 2007.

PENA, F. L. A,; RIBEIRO-FILHO, A. Da pesquisa em Ensino de Física para a sala de aula: um estudo sobre esta perspectiva. In: VI Encontro Nacional de Pesquisa em Educação em Ciências, 2007, Florianópolis. Anais... VI ENPEC, 2007.

PERES, K. K.; ARRUDA, S. M.; PASSOS, M. M.; STANZANI, E. L. Um estudo sobre o aprendizado do conhecimento científico no Museu de Ciência e Tecnologia de Londrina. In: XX Encontro Anual de Iniciação Científica, 2011, Ponta Grossa. Anais... XX EAIC, 2011.

PIMENTA, S.G. Formação de professores: identidade e saberes docentes. In: PIMENTA, S.G. (org.). Saberes pedagógicos e atividades docentes. $8^{\mathrm{a}}$ ed. São Paulo: Cortez, 2012.

RIBAS, Jeferson Ferreti. A Aprendizagem para a Pesquisa em um grupo PIBID/Química. 2018. 122 f. Dissertação (Mestrado em Ensino de Ciências e Educação Matemática) - Universidade Estadual de Londrina, Londrina, 2018.

SANGIOGO, F. A.; HALMENSCHLAGER, K. R.; HUNSCHE, S.; MALDANER, O. A. Pressupostos epistemológicos que balizam a Situação de Estudo: algumas implicações ao processo de ensino e à formação docente. Ciência \& Educação, v. 19, n. 1, p. 35-54, 2013.

SILVA, S. P.; PASSOS, M. M.; ARRUDA, S. M. As “memórias” e sua utilização no Grupo das Quartas. In: XIX Encontro Anual de Iniciação Científica, 2010, Guarapuava. Anais... XIX EAIC, 2010.

STANZANI, E. L. O papel do PIBID na formação inicial de professores de química na Universidade Estadual de Londrina. Dissertação de Mestrado (Ensino de Ciências e Educação Matemática). Universidade Estadual de Londrina, Londrina, 2012, 86p.

STANZANI, E. L.; PASSOS, M. M.; ARRUDA, S. M. Reflexões sobre a aprendizagem científica em ambientes informais de educação. In: X Congresso Nacional de Educação, 2011, Curitiba. Anais... X EDUCERE, 2011.

TARDIF, M. Saberes docentes e formação profissional. Petrópolis: Vozes, 2014.

TEIXEIRA, L. A. Tornando-se pesquisadores: um estudo a partir da análise de memórias de um grupo de pesquisa em educação em ciências e matemática. 2013. 179 f. Dissertação (Mestrado em Ensino de Ciências e Educação Matemática) - Universidade Estadual de Londrina, Londrina, 2013. 
TEÓFILO, R. F.; BRAATHEN, P. C.; RUBINGER, M. M. M. Reação Relógio iodeto/iodo com material alternativo de baixo custo e fácil aquisição. Química Nova na Escola, n. 16, p. 41-44, 2002.

THOMAZ, M. F. A experimentação e a formação de professores de ciências: uma reflexão. Caderno Catarinense de Ensino de Física, v.17, n. 3, p. 360-369, 2000.

\section{NOTAS}

${ }^{1}$ Ao construir um esboço do perfil do grupo, buscamos mapear alguns aspectos presentes nos registros analisados evidenciando características que representam tal grupo.

${ }^{2}$ PASSOS, M. M.; ARRUDA, S. M.; PRINS, S. A.; CARVALHO, M. A. Memórias: uma metodologia de coleta de dados - dois exemplos de aplicação. Revista Brasileira de Pesquisa em Educação em Ciências. v.8, n. 1, 2008.

${ }^{3}$ Entendemos como estratégias de ensino os meios utilizados pelo professor para facilitar o processo de aprendizagem dos alunos. De acordo com Masetto (2003), fazem parte dessa definição a organização do espaço utilizado, os materiais necessários, os recursos audiovisuais, as visitas técnicas, os estudos de casos, as discussões em grupos, o uso da internet, entre inúmeras opções.

${ }^{4}$ HERRON, J. D. Piaget for Chemists - explaining what "good" students cannot understand. Journal of Chemical Education, Easton, v. 52, n. 3, p. 146-150, mar. 1975. Tradução: prof. Antonio Sergio K. Milagre.

${ }^{5}$ OLIVEIRA, J. R. S. A perspectiva Sócio-Histórica de Vygotsky e suas Relações com a Prática da Experimentação no Ensino de Química. Alexandria - Revista de Educação em Ciência e Tecnologia, v.3, n.3, p. 25-45, nov. 2010.

${ }^{6}$ BOFF, E. T. O.; PANSERA-de ARAÚJO, M. C. A significação do conceito de energia no contexto da situação de estudo alimentos: produção e consumo. Revista Brasileira de Pesquisa em Educação em Ciências. V. 11, n.1, p. 123-142, 2011.

${ }^{7}$ FREITAS FILHO, J. R. Utilização de diferentes Estratégias de Ensino a partir de Situação de Estudo. Revista Brasileira de Ensino de Ciências e Tecnologia, v. 3, n. 2, maio/ago. 2010.

${ }^{8}$ ARRUDA, S. M.; PASSOS, M. M.; PIZA, C. A. M.; FELIX, R. A. B. O Aprendizado Científico no Cotidiano. Ciência \& Educação, Bauru, v. 19, n. 2, p. 481-498, 2013.

${ }^{9}$ Considerando que os coordenadores e professores universitários participam de todas as reuniões e conduzem as discussões bem como os encaminhamentos, estes apresentam falas em todas as memórias, portanto optamos por não quantificá-las.

${ }^{10}$ São considerados como frequência de participação momentos em que determinado participante expõe suas ideias acerca do tópico em questão, independente da quantidade de falas.

Submetido em 15/12/2017

Aprovado em 16/01/2019

\section{Contato:}

Rodovia Celso Garcia Cid | PR 445 Km 380 | Campus Universitário. Departamento de Química.

Cx. Postal 10.011 | CEP 86.057-970 | Londrina - Paraná - Brasil. 